\title{
PEMANFAATAN ELEMEN DAUR ULANG PADA DESAIN TAMAN LALU LINTAS TK BAITHANI TENGGER PADA KEGIATAN SERVICE LEARNING KELAS ARSITEKTUR ANAK DI NONGKOJAJAR - JAWA TIMUR
}

\author{
Christine Wonoseputro ${ }^{*}$, Jessica Muljadi ${ }^{2}$, Marcelina Lupita Surjanto ${ }^{3}$, Keshia Hanna Kumala ${ }^{4}$ \\ Stevanie Paulina ${ }^{5}$, Leonita Theodore ${ }^{6}$, Fransiskus Xaverius Jonathan Tjiptorahardjo ${ }^{7}$, \\ Wilson Tedja ${ }^{8}$ \\ 1,2,3,4,5,6,7,8 Fakultas Teknik Sipil dan Perencanaan, Program Studi Arsitektur, Universitas Kristen Petra \\ Л. Siwalankerto 121-131, Surabaya 60236 \\ * Penulis korespondensi; email: christie@petra.ac.id
}

\begin{abstract}
Abstrak: Kegiatan Service Learning (SL) yang diadakan di Tk Baithani Tengger dalam rangka mata kuliah KKP Arsitektur Anak bukan hanya sekedar memberikan pelayanan masyarakat. Pada pelaksanaan SL mata kuliah KKP Arsitektur Anak, subyek pembelajaran dilatih untuk mampu menganalisa masalah sosial yang dihadapi oleh masyarakat untuk selanjutnya mengangkat problem tersebut ke dalam permasalahan desain. Selain itu para mahasiswa juga belajar untuk bekerja sama dengan segala pihak dalam pelaksanaan proyek secara nyata, khususnya dalam pemanfaatan bahan bekas (limbah) keramik untuk dijadikan bahan penutup jalan bagi anak-anak di taman lalu lintas milik TK Baithani Tengger.
\end{abstract}

Kata kunci: Taman lalu lintas; Arsitektur anak; metode service learning; kegiatan akademis; TK Baithani Tengger; bahan daur ulang

\begin{abstract}
The Service Learning method that being done in TK Baithani Tengger, was not just a community service activity. In the process of learning, students were trained in order to be able to analyze community problems and continued to take it as design problem of their project. In the other side, students also learn to cooperate with all parties in the implementation of real project development, especially by utilizing ceramic scrap materials in order to be used as finishing elements of TK Baithani Tengger's traffic education park.
\end{abstract}

Keywords: Traffic park; Children's architecture; service learning methods; academic program; Baithani Tengger Kindergarten; recycle materials

\section{PENDAHULUAN}

Perkembangan pola pikir anak pada tahap usia golden age merupakan sebuah perkembangan positif dalam membentuk satu pribadi yang baik. Hal ini tentunya memerlukan dukungan dari para orang tua dan orang dewasa dalam mengasah perkembangan mereka, baik sensorik maupun motorik balita. ${ }^{1}$

Melihat pentingnya pembelajaran tersebut, pendidikan dini bagi anak- anak, sudah menjadi suatu kebutuhan yang mendasar. Fasilitas pendidikan balita yang didirikan oleh Yayasan Baithani Teng-

1 Berdasarkan data statistik, pada usia 0-1 bulan balita sudah mampu melihat dan menangkap warna dasar (merah, kuning, biru). Warna memliki peranan penting dalam melatih visual balita. ger yang hadir dalam bentuk sarana Pendidikan Anak Usia Dini (PAUD Baitani) dan juga Taman Kanak-Kanaknya merupakan jawaban atas kebutuhan mendasar akan fasilitas pendidikan anak usia dini yang sudah sepatutnya hadir di tengahtengah masyarakat Nongkojajar.

TK Baithani Tengger merupakan sarana pendidikan yang terletak dalam kompleks sekolah Kristen Baithani Tengger di desa Wonosari, Kecamatan Tutur, Nongkojajar.

Sarana sekolah telah dilengkapi dengan berbagai fasilitas dan media yang cukup untuk fasilitas penunjang belajar pada anak, seperti contohnya ruang kelas, area baca, area mandi bola, taman bermain, serta fasilitas bermain yang lain. Berdasarkan hasil pengamatan tim SL KKP Arsitektur Anak, ada berbagai fasilitas dan media, hanya 
belum direncanakan dengan baik sehingga zona maupun fasilitas yang sudah ada tercampur antara satu dengan yang lain dan kurang desain terkesan tidak terencana dengan matang.
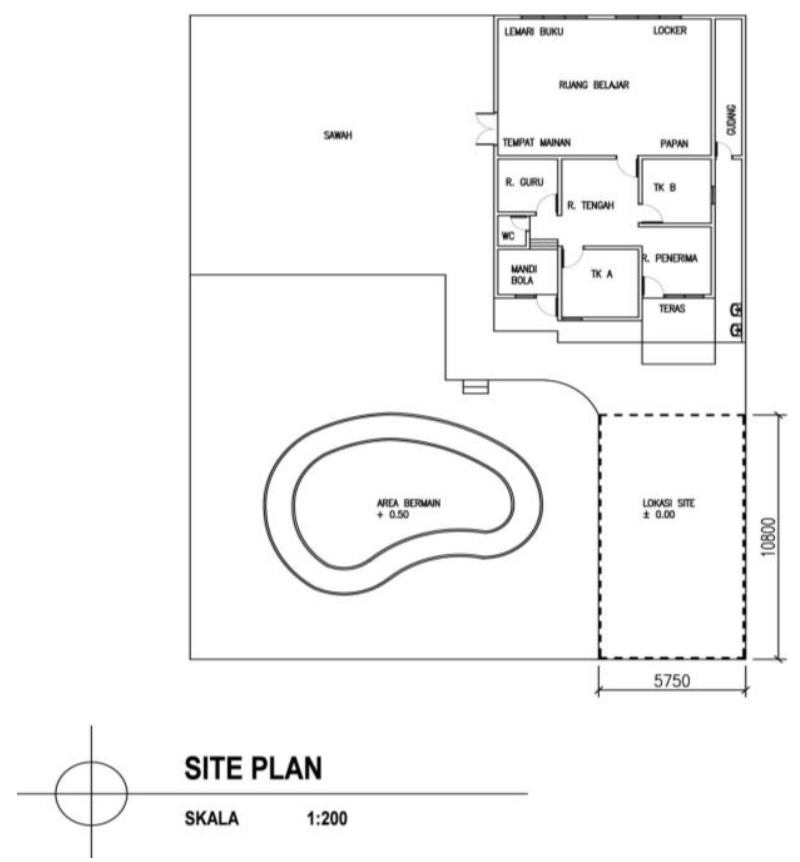

Gambar 1. Layout Plan eksisiting Gedung TK Baithani Tengger - Wonosari

Mencermati layout eksisiting dari sekolah, maka gagasan akan proses penataan ulang (re-desain) serta pemanfaatan lahan-lahan sekitar sekolah yang ada untuk menjadi lingkungan belajar pasif bagi anak secara efektif dan efisien, membutuhkan kecermatan serta kreatifitas tersendiri. Hal ini dikarenakan pula karena faktor keterbatasan ekonomi, serta perlu adanya kegiatan pemberdayaan masyarakat serta warga sekolah, agar kegiatan ini selanjutnya juga bisa dilanjutkan secara berkesinambungan oleh masyarakat itu sendiri, sesuai dengan prinsip service learning yaitu: To Build Partnership atau proses "Kemitraan".

\section{KAJIAN PUSTAKA}

\section{Perkembangan Kognitif Anak}

Menurut teori Jean Piaget (dalam Santrok, 2007: 246 dan Suryanto, 2005), perkembangan kognitif anak dibagi menjadi beberapa fase berdasarkan usia, yaitu:
a. Fase Sensorimotorik (usia 0-2 tahun)
b. Fase Praoperasional (usia 2-7 tahun)
c. Fase Operasi Konkret (usia 7-11 tahun)
d. Fase Operasi Formal (usia 11-15 tahun)

Anak usia 4-5 tahun yang berada dalam fase praoperasional memiliki perilaku signifikan, di antara- nya menggunakan pendekatan egosentrik untuk mengakomodasi tuntutan lingkungan, semua hal bermakna dan berkaitan dengan "aku", bahasa berkembang dengan cepat, mengasosiasikan kata dengan objek, dan mengeksplorasi lingkungannya (Hurlock, E.B, 2007). Hal ini membuat fasilitas yang didesain untuk nak pada tahapan tersebut harus mulai mengajarkan bagaiman mereka berbagi, pengenalan akan lingkungan sosial, serta mulai mengajarkan anak bagaimana mengendalikan egosentrisnya. ${ }^{2}$

Anak usia dini dalam lima tahun pertama mengalami kecepatan perkembangan yang sangat pesat. Hal ini dinyatakan (Suyanto, 2005: 7) bahwa anak usia dini sedang mengalami pertumbuhan dan perkembangan baik secara fisik maupun mental yang sangat pesat". Tidak hanya secara fisik namun juga secara sosial, emosional, intelegansi, dan bahasa. Dalam hal ini akan sangat baik jika memberikan stimulasi pada anak usia 4-5 tahun agar dapat berkembang secara maksimal, salah satunya melalui stimulasi warna. Dalam perwujudannya dapat melalui desain yang memiliki warna yang menarik. Menurut Fudyartanta (2011: 182) dari melihat obyek benda (bentuk dan warna) masuk ke dalam mata melalui lensa mata terus diterima oleh bintik kuning diteruskan oleh syaraf mata (penglihatan) ke otak pusat. Melalui proses penglihatan (warna) tersebut dapat merangsang perkembangan syaraf otak khususnya syaraf otak anak usia dini yang baru belajar mengenal obyek benda (warna) (Day, Christopher \& Midbjer, Anita, 2007). Desain dengan warna yang menarik diharapkan dapat menarik minat anak untuk belajar dengan lebih maksimal. Sebagaimana pendapat bahwa menyebut, mengklasifikasikan, membedakan, dan menghitung warna merupakan kemampuan kognitif-logika anak yang digunakan sebagai dasar melakukan asimilasi, adaptasi, dan akomodasi terhadap lingkungan dan situasi baru. Kemampuan tersebut membentuk skema baru, sehingga anak memiliki kemampuan aktivitas memproses informasi (Rasyid, Mansyur, dan Suratno. 2009 : 252)

\section{Perkembangan Motorik Anak}

Perkembangan motorik merupakan perkembangan dari unsur kematangan dan pengendalian gerakan tubuh yang erat kaitannya dengan perkembangan pusat motorik di otak. Perkembangan motorik merupakan perkembangan pengendalian gerakan jas-

2 Pada desain Taman lalu Lintas, anak akan difasilitasi dalam zona menunggu, belajar mengantri, bergiliran dalam menggunakan kendaraan, dan bermain bersama sama. 
maniah melalui kegiatan pusat syaraf, urat syaraf dan otot terkoordinasi (Hurlock: 1998). Keterampilan motorik anak terdiri atas keterampilan motorik kasar dan keterampilan motorik halus. Keterampilan motorik anak usia 4-5 tahun lebih banyak berkembang pada motorik kasar, setelah usia 5 tahun baru terjadi perkembangan motorik halus (Hurlock, E.B, 1998)

Menurut Papalia tulang dan otot anak pra-sekolah semakin kuat, dan kapasitas paru mereka semakin besar memungkinkan mereka untuk berlari, melompat, dan memanjat lebih cepat, lebih jauh, dan lebih baik (Papalia, Diane, E. et al. 2008). Pada usia 4 tahun anak-anak masih suka jenis gerakan sederhana seperti berjingkrak-jingkrak, melompat, dan berlari kesana kemari, hanya demi kegiatan itu sendiri tapi mereka sudah berani mengambil resiko. Walaupun mereka sudah dapat memanjat tangga dengan satu kaki pada setiap tiang anak tangga untuk beberapa lama, mereka baru saja mulai dapat turun dengan cara yang sama. Pada usia 5 tahun, anak-anak bahkan lebih berani mengambil resiko dibandingkan ketika mereka berusia 4 tahun. Mereka lebih percaya diri melakukan ketangkasan yang mengerikan seperti memanjat suatu obyek, berlari kencang dan suka berlomba dengan teman sebayanya bahkan dengan orang tuanya (Santrock, 1995 : 225).

Pada usia 4 tahun, koordinasi motorik halus anakanak telah semakin meningkat dan menjadi lebih tepat. Kadang-kadang anak-anak usia 4 tahun sulit membangun menara tinggi dengan balok karena mereka ingin menempatkan setiap balok secara sempurna, mereka mungkin tidak puas atas balokbalok yang telah disusun. Menurut Santrock, pada usia 5 tahun, koordinasi motorik halus anak-anak semakin meningkat. Tangan, lengan, dan tubuh bergerak bersama di bawah komando yang lebih baik dari mata (Santrock, 1995) Hal ini membawa pemikiran bahwa menciptakan ruang belajar bagi anak haruslah menarik secara visual, merangsang aktivitas, kedinamisan, namun juga harus tetap aman bagi aktivitas anak-anak.

\section{TAHAPAN KEGIATAN SERVICE LEARNING}

\section{Tahap Pendalaman Teori}

Proses desain pada taman bermain PAUD Baithani Tengger adalah proses pelatihan dan pelayanan dengan meliputkan beberapa langkah seperti pembelajaran teori lalu melakukan kegiatan observasi dan akhirnya mencapai perencanaan desain serta pelaksanaannya. Pembelajaran teori dengan melibatkan dosen dan mahasiswa dilakukan di dalam kelas selama sekitar 14 minggu untuk lebih mengenal karakter dan aktivitas anak. Selain itu, proses ini bertujuan untuk mengetahui faktor-faktor yang mempengaruhi proses desain untuk anak seperti jenis kegiatan, kebutuhan, dan pola perilaku anak. Melalui kegiatan ini, mahasiswa dibekali pengetahuan secara teoritis untuk menjadi dasar dalam pelaksanaan kegiatan service learning itu sendiri. Kegiatan ini juga merangsang rasa peduli kita terhadap keinginan dan kebutuhan anak khususnya pada umur 4-5 tahun yang dipahami bahwa anak pada usia sedemikian sangat tertarik dengan rangsangan inderawi, terutama secara visual, dalam hal ini melalui media warna. (Hurlock, 1998).

\section{Tahapan Observasi}

Untuk mengenal lebih dalam, mahasiswa mengadakan observasi lapangan pada tempat-tempat yang sering dikunjungi anak untuk bermain, yaitu fasilitas bermain Kids Kingdom di Surabaya Night Carnival yang menjadi wadah bagi anak-anak, tidak hanya sebagai sarana bermain tapi juga memberikan sarana edukasi yang memudahkan anak untuk cepat belajar melalui wahana yang ada. Melalui kegiatan ini, peserta didik belajar bahwa berbagai bentuk serta detail yang terdapat dalam desain booth masing-masing wahana yang diperuntukan untuk anak-anak memiliki karakter yang khas, bentuk yang bersifat sederhana untuk anakanak serta mudah dicerna, ekspresi yang cenderung dinamis dan berkarakter analogi dari bentukanbentukan yang sudah sangat bersahabat dengan dunia anak-anak, serta yang tidak kalah menarik adalah penggunaan skema warna yang cenderung merupakan warna cerah (bright colour).

Pada tahapan selanjutnya, mahasiswa mengadakan diskusi kelompok dalam kelas tentang teori dan studi kasus yang dilakukan di lapangan sebelum kemudian mengaplikasikan pengetahuan mereka akan teori tersebut melalui kasus nyata di lapangan.

\section{Tahapan Kegiatan SL}

Sebelum menuju lokasi SL untuk melakukan kegiatan live-in, mahasiswa melakukan pengembangan konsep yang berupa gagasan pembuatan taman lalu lintas untuk anak-anak. Kegiatan ini juga memperhatikan hal-hal yang dipelajari dalam tahapan sebelumnya yang berkaitan dengan karakter yang disukai oleh anak-anak serta membuat anak tertarik untuk menggunakannya. Hal tersebut mempengaruhi konsep pemilihan material serta pengaplikasian skema warna pada desain taman edukasi dan taman lalu lintas. Setelah melakukan serangkaian observasi lapangan, peserta KKP Arsitektur Anak memilih untuk memanfaatkan limbah, seperti bekas pagar, penataan tanaman yang ada di area sekitar, serta pemanfaatan keramik yang berupa mozaik berwarna-warni, yang banyak ditemukan di sekitar area sekolah dan 
dipergunakan sebagai jalan yang menandai batas antara taman basah dengan jalan pada area taman edukasi. Hal ini didasarkan atas pemikiran dan pemberdayaan material daur ulang, serta melatih masyarakat untuk menghargai limbah lingkungan menjadi sesuatu yang lebih bernilai karena proses desain. Kegiatan dilanjutkan dengan pemilahan limbah, mana yang dapat dimanfaatkan dan mana yang tidak dapat dimanfaatkan. Pada proses pemanfaatan limbah keramik sebagai elemen mozaik, bertujuan untuk membedakan tekstur yang ada pada taman edukasi lalu lintas sehingga anak akan belajar secara indrawi juga, untuk membedakan bagian rumput pada area taman bermain dan bagian yang bertekstur sebagai jalan mobilmobilan. Tekstur yang ingin diperkenalkan dalam rangka pengenalan tekstur bagi anak meliputi karakter tekstur dan pola warna:

Tabel 1. Penerapan Tekstur dan Warna

\begin{tabular}{|c|c|c|}
\hline Fungsi & Pola / Tekstur & Warna \\
\hline Penghijauan & Berumput (kasar) & Hija \\
\hline $\mathrm{Pec}$ & Ber & $\begin{array}{l}\text { Pola } \\
\text { Abu- }\end{array}$ \\
\hline & & tua \\
\hline Area bermain & Pola bulat dan lengkung & Warna-war \\
\hline
\end{tabular}

Survei lokasi secara langsung bertujuan untuk mengetahui keadaan lokasi yang ada untuk disesuaikan dengan desain dasar yang sudah dibuat, seperti pengukuran lokasi yang akan diaplikasikan ke dalam desain akhir.

Tahap akhir dari desain zona taman bermain PAUD Baithani Tengger adalah penyesuaian desain dasar dengan keadaan lokasi, mulai dari ukuran yang dibutuhkan hingga material yang digunakan. Material daur ulang terutama mozaik dan batang bekas pagar untuk rambu mulai didesain ulang agar detailnya terolah sehingga aman bagi anakanak.

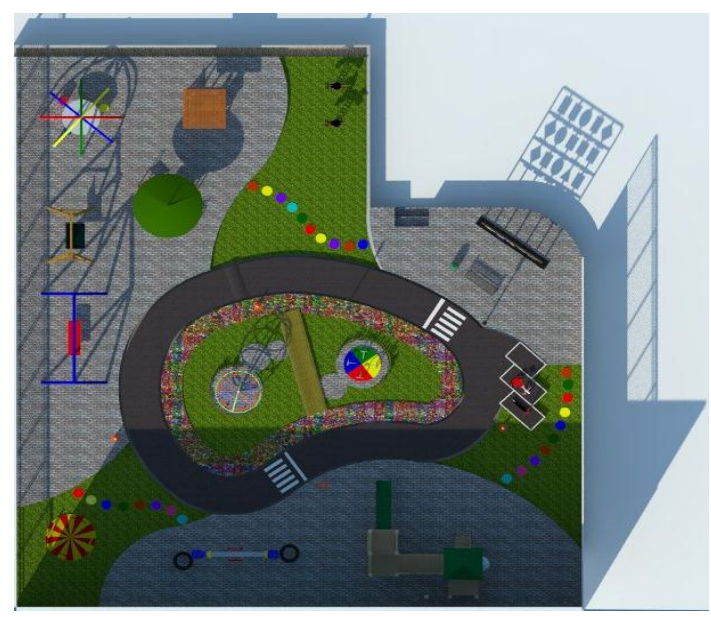

Gambar 2. Layout Plan Desain Taman lalu Lintas
Proses pelaksanaan akhir desain dilakukan setelah desain telah benar-benar selesai. Pada awalnya, dilakukan pembongkaran dan pemindahan taman bermain yang sudah ada. Kemudian, dilanjutkan dengan mulai membuat lantai taman khususnya jalan pedestrian. Jalan pedestrian dikerjakan oleh mahasiswa selama 2 hari dengan dibantu oleh pengarahan tukang setempat dan warga sekitar sekolah. Proses realisasi desain selanjutnya dilaksanakan oleh tukang serta warga setempat secara swadaya. Hasil desain yang ada adalah pengaplikasian kebutuhan anak akan warna berupa lantai keramik mozaik berwarna-warni. Lantai keramik tersebut diaplikasikan ke dalam desain jalan pedestrian pada taman lalu lintas. Untuk memenuhi kebutuhan anak-anak akan warna, mozaik ini disusun dengan pola serta warna yang beragam, dengan pemilihan skema warna "bright colour"/ karakter warna cerah. Pemasangan mozaik sendiri dilakukan secara acak dalam berbagai warna, bentuk, dan ukuran untuk membuatnya terlihat lebih menarik minat anak-anak untuk belajar dengan maksimal di taman lalu lintas yang dibuat.

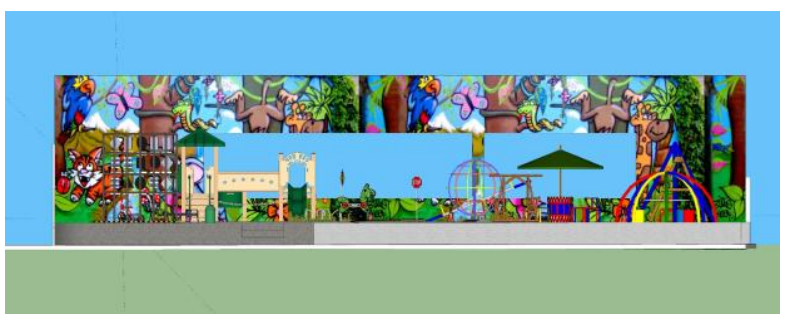

Gambar 3. Konsep taman lalu lintas seperti menciptakan suasana kota mainan

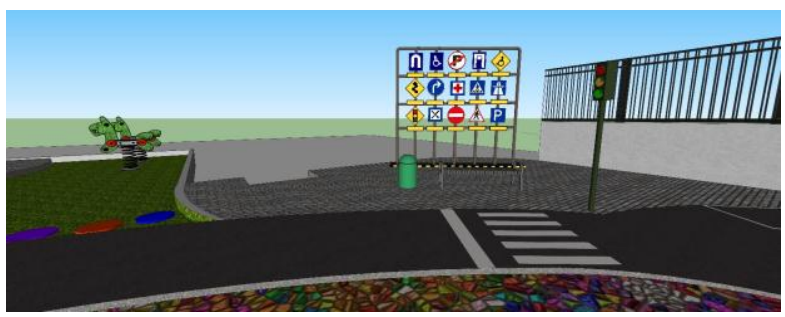

Gambar 4 Detail Taman lalu lintas

Pada bagian akhir penyelesaian pemasangan mozaik, kelas dibantu oleh seorang tukang yang merupakan warga lokal, untuk memastikan pemasangan keramik yang benar dan aman bagi anakanak, dengan menaburkan rabatan yang rata dan memukulkan mosaik agar memperoleh ketinggian yang rata untuk mencegah ujung yang menonjol. Penyelesaian akhir yang dititipkan untuk dikerjakan warga adalah penggunaan dan pemakaian campuran polyester resin sebagai lapisan pelindung sehingga mosaic lebih menempel serta permukaan mosaik menjadi lebih rata dan lebih aman untuk dipergunakan. 


\section{KESIMPULAN}

Melalui proses realisasi desain taman lalu lintas di PAUD Baithani Tengger, mahasiswa mendapatkan banyak pengalaman baru yang kebanyakan tidak didapat melalui perkuliahan teori di dalam kelas. Proses belajar Service Learning sendiri telah menanamkan beberapa hal penting yang lebih banyak dipelajari secara pragmatis daripada secara teoritis. Pengalaman tersebut antara lain:

1. Mengenal pembelajaran lapangan tentang bagaimana cara memasang mozaik dengan tepat. Melalui proses belajar secara Service Learning, mahasiswa sendiri banyak mendapatkan tambahan wawasan dan pengalaman praktek lapangan tentang pengetahuan dan pengaplikasian bahan serta bagaimana menerapkan pengetahuan bahan ke dalam desain yang sesungguhnya.

2. Belajar memahami kebiasaan yang warga lokal dan mengenal local wisdom. Dalam kegiatan kali ini, mahasiswa sempat bertemu dengan para guru lokal yang mengajar di TK Baithani Tengger, belajar bersama anak-anak panti, bertemu dengan beberapa mahasiswa dari perguruan tinggi swasta lain dari kota Malang yang secara kebetulan juga melakukan praktek kerja lapangan di lokasi yang sama, serta bekerja sama dengan warga Tengger. Selain itu dalam kegiatan SL semester gasal 2014-2015 ini, mahasiswa Arsitektur Anak sempat bekerja dalam time schedule yang bersamaan dengan mahasiswa dari Program Studi desain Interior Universitas Kristen Petra. Hal ini membuat mahasiswa bisa saling belajar, saling memahami, dan saling berkolaborasi bersama untuk memecahkan masalah yang dihadapi.

3. Tidak hanya itu, disini mahasiswa mendapatkan pemahaman baru bahwa bahan bekas dapat menjadi sesuatu yang berguna dan menarik apabila penggunaannya disesuaikan dengan karakteristik, kebiasaan, serta hal-hal yang disukai oleh anak-anak. Hal ini membawa bagaimana seharusnya pemahaman teori dibawa dalam taraf selangkah lebih maju, dan memahami bahwa apa yang dipelajari di kelas seringkali berbicara secara berbeda dengan di lapangan. Dalam kasus ini, mahasiswa melakukan kreativitas desain daur ulang, pemilihan warna dan finishing, pemilahan jenis keramik, dan menyusun keramik-keramik dalam pola mozaik yang digunakan sebagai jalan pedestrian di taman lalu lintas. Namun pada saat pengaplikasian sering kali material daur ulang membawa kesulitan tersendiri dalam rangka mencapai kesempurnaan kualitas desain yang diharapkan. Hal ini telah juga membuat ketrampilan serta kreativitas mahasiswa juga menjadi lebih terasah.
Pemanfaatan material daur ulang di lapangan, khususnya pemanfaatan mozaik bahan bekas keramik yang berhubungan erat dengan warna dan fungsi, yang mana masih harus terus disempurnakan dan dievaluasi penggunaannya, serta dampaknya bagi kegiatan anak-anak di TK Baithani Tengger.

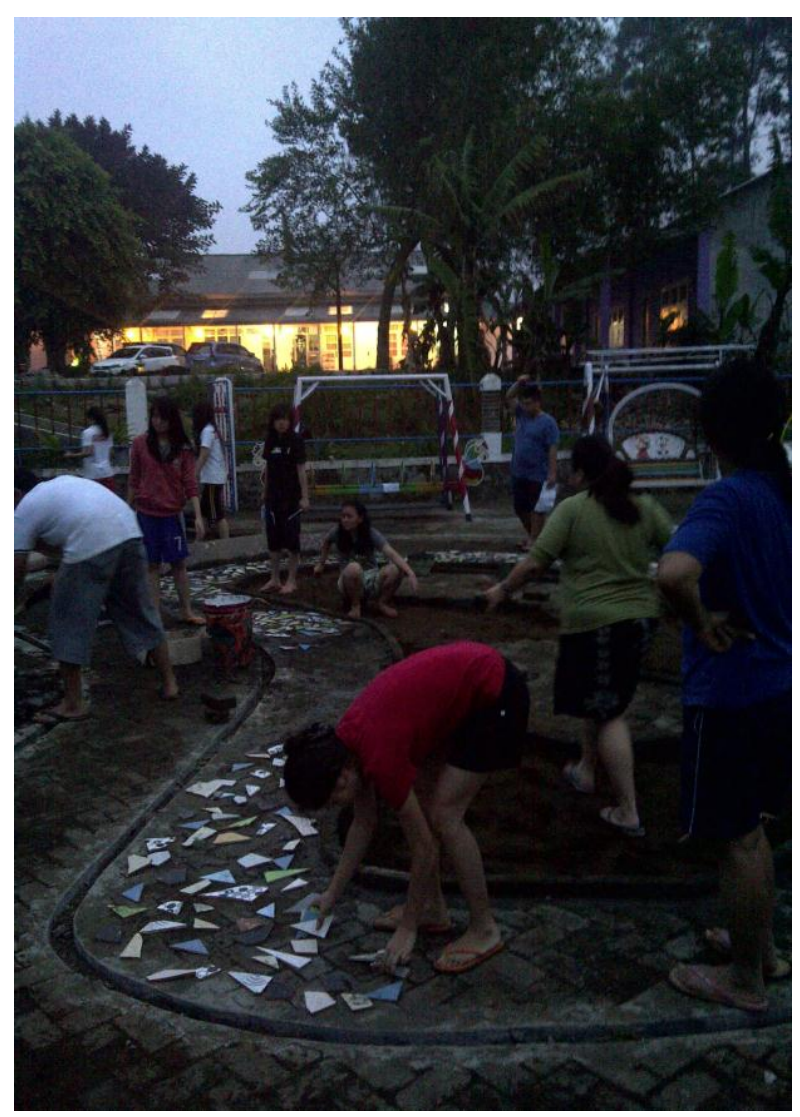

Gambar 5. Pemasangan mosaic di lapangan

Sebuah pekerjaan rumah yang besar untuk dapat terus memantau dan menyempurnakan karya desain bersama warga masyarakat dalam rangka mendapatkan hasil yang murah, menarik, dan meriah, namun juga tetap memperhatikan sisi dan fungsi desain yang tetap "ramah bagi anak-anak."

\section{UCAPAN TERIMA KASIH}

Keluarga besar TK Baithani Tengger Nongkojajar, Ibu Mamiek selaku kepala sekolah TK Baithani Tengger beserta segenap guru di Baithani yang membantu kami dalam memfasilitasi kegiatan SL di Nongkojajar.

Bapak Agustinus Suwito selaku pengurus yayasan Baithani Tengger yang telah menjadi mitra belajar SL Arsitektur Anak yang telah dengan setia dan sabar mendampingi dan berdiskusi atas masalahmasalah lapangan yang dihadapi selama live in berlangsung. 


\section{DAFTAR PUSTAKA}

Day, Christopher \& Midbjer, Anita (2007), Environment and Children, Architectural Press, London.

Fudyartanta, K. (2011). Psikologi umum I \& II. Yogyakarta: Pustaka Pelajar.

Hurlock, E.B. (1998). Perkembangan anak jilid 1. Jakarta: Erlangga.

Hurlock, E.B. (2007). Perkembangan anak. (Mila Rachmawati \& Anna Kuswanti). Jakarta: Erlangga.
Hurlock, E.B. 1978. Perkembangan anak jilid 2. (Med. Meitasari Tjandrasa). Jakarta: Erlangga.

Papalia, Diane, E., et al. (2008). Human development (Psikologi perkembangan). (A. K. Anwar). Jakarta: Kencana Prenada Media Grup.

Rasyid, H., Mansyur \& Suratno. (2009). Asesmen perkembangan anak usia dini. Yogyakarta: Multi Pressindo.

Santrock, J.W. (1995). Lifes span development. Jakarta: PT Erlangga.

Suyanto, S. (2005). Dasar-Dasar pendidikan anak usia dini. Yogyakarta: Hikayat. 